\title{
PENGARUH LINGKUNGAN FISIK TERHADAP KEJADIAN TB PARU
}

\author{
Sri Rahayu, Muhammad Ali Sodik \\ STIKes Surya Mitra Husada \\ srirahayu050270@gmail.com, alisodik2012@gmail.com
}

\begin{abstract}
Abstrak
Sampai kini, Tuberkulosis (TBC) masih menjadi masalah kesehatan masyarakat yang penting di dunia. Menurut laporan WHO, di seluruh dunia setiap tahun ditemukan sekitar 8 juta kasus baru. Indonesia merupakan negara penyumbang kasus TBC terbesar ketiga setelah India dan Cina dengan perkiraan jumlah kasus pada 2003 adalah 627.047 penderita dan 281.946 kasus merupakan TBC paru BTA positif. Lingkungan fisik yang kurang baik merupakan media penularan TBC. Dengan memperbaiki lingkungan fisik diharapkan bisa mengurangi penularan TBC
\end{abstract}

Kata Kunci : Lingkungan Fisik, TB Paru

\section{Latar Belakang Masalah}

Tuberkulosis adalah penyakit saluran nafas yang disebabkan oleh mycobacterium, yang berkembang biak di dalam bagian tubuh dimana terdapat banyak aliran darah dan oksigen. Infeksi bakteri ini biasanya menyebar melewati pembuluh darah dan kelenjar getah bening, tetapi secara utama menyerang paru-paru.

Di Indonesia TB Paru merupakan salah satu masalah kesehatan utama masyarakat. Jumlah pasien TB Paru di Indonesia merupakan peringkat ke empat dunia setelah India, Cina, Afrika Selatan dengan prevalensi TB 285 per 100. 000 penduduk atau sebanyak 302. 861 kasus pada tahun 2010 (WHO, Global Tuberculosis Control, 2010).
Lingkungan rumah yang dapat mempengaruhi tingginya kejadian tuberkulosis paru adalah lingkungan rumah yang kurang sehat misalnya kurang adanya fasilitas ventilasi yang baik, pencahayaan yang buruk di dalam ruangan, kepadatan hunian dalam rumah dan bahan bangunan didalam rumah. Selain lingkungan rumah yang mempengaruhi kejadian tuberkulosis keadaan lingkungan fisik, lingkungan biologis dan lingkungan sosial yang kurang baik juga akan dapat merugikan kesehatan dan dapat mempengaruhi penyakit tuberkulosis dan pada akhirnya mempengaruhi tingginya kejadian tuberkulosis (Muaz, 2014).

Permasalahan tersebut perlu dilakukan perbaikan lingkungan fisik rumah penderita TB paru. Kondisi rumah yang baik penting 
untuk mewujudkan masyarakat yang sehat. Rumah dikatakan sehat apabila memenuhi persyaratan empat hal pokok antara lain ; memenuhi kebutuhan fisiologis seperti pencahayaan, penghawaan, ruang gerak yang cukup dan terhindar dari kebisingan yang mengganggu, memenuhi kebutuhan psikologis seperti "Privacy" yang cukup dan komunikasi yang baik antar penghuni rumah, memenuhi persyaratan pencegahan penyakit menular yang meliputi penyediaan air bersih, pembuangantinja dan air limbah rumah tangga, bebas dari vektor penyakit, kepadatan hunian yang tidak berlebihan, sinar matahari yang cukup, makanan dan minuman yang terlindung dan pencemaran serta pencahayaan dan penghawaan yang cukup serta memenuhi persyaratan pencegahan terjadinya kecelakaan baik yang berasal dari dalam maupun dari luar rumah (Kep Men Kes RI No. 829, 1999).

Lingkungan fisik rumah penderita TB parusangat berhubungan dengan tingkat penyebaran penyakit. TB Paru. Kondisi fisik rumah penderita TB paru yang baik akan menghambat perkembangan TB Paru. Diharapkan dengan mengetahui lingkungan fisik rumah penderita TB Paru diharapkan bisa mengurangi angka penderita TB Paru di wilayah Puskesmas Lengkong. Dengan mengetahui kondisi sanitasi rumah diharapkan bisa bekerja sama dengan pemerintah menentukan skala prioritas pembangunan sarana pra sarana, khususnya sanitasi rumah.

\section{Kasus}

Di Indonesia TB Paru merupakan salah satu masalah kesehatan utama masyarakat. Jumlah pasien TB Paru di Indonesia merupakan peringkat ke empat dunia setelah India, Cina, Afrika Selatan dengan prevalensi TB 285 per 100.000 penduduk atau sebanyak 302. 861 kasus pada tahun 2010 (WHO, Global Tuberculosis Control, 2010).

Lingkungan rumah yang dapat mempengaruhi tingginya kejadian tuberkulosis paru adalah lingkungan rumah yang kurang sehat misalnya kurang adanya fasilitas ventilasi yang baik, pencahayaan yang buruk di dalam ruangan, kepadatan hunian dalam rumah dan bahan bangunan didalam rumah. Rumah penderita TB Paru di Kecamatan Lengkong didapatkan lingkungan fisik rumah penderita TB Paru semua kurang memenuhi syarat rumah sehat. Syarat rumah sehat yang terpenuhi hanya lantai saja. Untuk Jendela, vetilasi, langit-langit dan kelembaban tidak memenuhi syarat. Hal ini jika dibiarkan akan mempunyai dampak pada penularan TB Paru.

\section{Tinjauan Pustaka}

Lingkungan fisik rumah adalah lingkungan fisik sehari-hari yang dialami dan dijalani penderita TB paru atau kondisi rumah dan berbagai perangkat yang ada di dalamnya yang meliputi bentuk, kondisi bangunan serta padat hunian dalam rumah 
merupakan hal yang mendasar yang dapa mempengaruhi penyembuhan TB paru yang selanjutnya berdampak pada kesehatan keluarga(Notoadmojo, 2003).

Penyakit TBC adalah suatu penyakit infeksi yang disebabkan oleh bakteri Mycobacterium tuberculosis. Bakteri ini berbentuk batang dan bersifat tahan asam sehingga dikenal juga sebagai Batang Tahan Asam (BTA). Bakteri ini pertamakali ditemukan oleh Robert Koch pada tanggal 24 Maret 1882, sehingga untuk mengenang jasanya bakteri tersebut diberi nama Baksil Koch. Bahkan, penyakitTBC pada paru-paru kadang disebut sebagai Koch Pulmonum (KP) (Depkes RI, 2006).

Jenis kuman tersebut adalah mycobacterium tuberculosis, mycobacterium africanum dan mycobacterium bovis. Basil tuberkulosis termasuk dalam genus mycobacterium, suatu anggota dari family dan termasuk dalam ordo Actinomycetales. Mycobacterium tuberculosis menyebabkan sejumlah penyakitberat pada manusia dan juga penyebab terjadinya infeksi tersering.

Basil-basil tuberkel didalam jaringan tampak sebagai mikroorganisme berbentuk batang, dengan panjang bervariasi antara 1 - 4 mikron dan diameter 0, 3-0, 6 mikron. Bentuknya sering agak melengkung dan kelihatan seperti manik-manik atau bersegmen. Basil tuberkulosis dapat bertahan hidup selama beberapa minggu dalam sputum kering, ekskreta lain dan mempunyai resistensi tinggi terhadap antiseptik, tetapi dengan cepat menjadi in aktif oleh cahaya matahari, sinar ultraviolet atau suhu lebih tinggi dari $60^{\circ} \mathrm{C}$. Sehingga itu bakteri tersebut sangat menyukai tempat - tempat yang gelap dan lembab, yang jauh dari sinar matahari secara langsung.

\section{Mycobacterium tuberculosis masuk} kedalam jaringan paru melalui saluran napas (droplet infection) sampai alveoli, terjadilah infeksi primer. Selanjutnya menyebar ke getah bening setempat dan terbentuklah primer kompleks. Infeksiprimer dan primer kompleks dinamakan TB primer, yang dalam perjalanan lebih lanjut sebagian besar akan mengalami penyembuhan.

Epidemiologi penyakit tuberkulosis paru adalah ilmu yang mengkaji frekwensi, distribusi serta determinan. Kajian tersebut menyangkut interaksi antara Mycobacterium tuberculosis sebagai bakteri (agent), manusia (host) dan lingkungan (environment). Disamping itu mencakup perkembangan dan penyebarannya, termasuk didalamnya juga mencakup prevalensi dan insidensi penyakit tersebut yang timbul dari populasi yang tertular (Depkes RI, 2006).

Dalam pencegahan penyakit TB Paru sangat perlu menjaga lingkungan yang sehat seperti pengaturan syarat - syarat rumah yang sehat diantaranya luas bangunan rumah, ventilasi pencahayaan 
dengan jumlah anggota keluarga serta kebersihan lingkungan tempat tinggal.

a). Pencegahan Tuberkulosis Paru

Berbasis Lingkungan

Pencegahan penyakit Tuberkulosis

Paru berbasis lingkungan dapat dilakukan dengan :

1). Satu kamar di huni tidak lebih dari 2 orang atau sebaiknya luas kamar lebih atau sama dengan 10 $\mathrm{m}^{2} /$ orang.

2). Lantai rumah sebaiknya di semen dan memperbaiki ventilasi serta menambah ventilasi buatan.

3). Selalu membuka pintu atau jendela terutama di pagi hari agar pencahayaan alami dapat masuk ke dalam rumah.

4). Menutup mulut bila batuk atau bersin bagi penderita maupun bukan penderita jika salin berdekatan.

5). Tidak meludah di sembarang tempat, upayakan meludah pada tempat yang terkena sinar matahari atau I tempat khusus seperti tempat sampah.

6). Menjemur tempat tidur bekas penderita secara teratur karena kuman tuberkulosis akan mati bila terkena sinar matahari.

7). Menjaga kebersihan diri, baik perorangan maupun keluarga serta menjaga kesehatan badan agar agar sistem imun senantiasa terjaga dan kuat.

8). Di usahakan tidur terpisah dengan penderita dan menjaga jarak aman ketika berhadapan dengan penderita TB Paru.

9). Bagi penderita di usahakan istirahat yang cukup dan makan makanan yangbergizi.

10) Hindari melakukan hal-hal yang dapat melemahkan sistem imunitas, seperti begadang dan kurang istirahat.

b. Pencegahan Berdasarkan Pengawasan Penderita dan Kontak

1). Meningkatkan daya tahan tubuh, terhadap bayi harus diberikan vaksinasiBCG.

2). Memberikan penyuluhan tentang penyakit TB Paru yang meliputi gejala, bahaya dan akibat yang akan ditimbulkan.

3). Isolasi, pemeriksaan kepada orangorang yang terinfeksi, pengobatankhusus TBC.

Pengobatan di rumah sakit hanya bagi penderita yang kategori berat yang memerlukan pengembangan program pengobatannya yang karena alas an-alasan sosial, ekonomi dan medis tidak dikehendaki pengobatan jalan.

4). Tuberkulin test bagi seluruh anggota keluarga dengan foto rontgen yang bereaksi positif, 
apabila cara-cara ini negative, perlu di ulang pemeriksaan tiap bulan selama 3 bulan.

5). Pengobatan khusus bagi penderita aktif. Obat-obat kombinasi yang telah ditetapkan oleh dokter diminum secara teratur selama sakit

\section{Pembahasan}

Lingkungan rumah dapat mempengaruhi tingginya kejadian tuberkulosis paru adalah lingkungan rumah yang kurang sehat misalnya kurang adanya fasilitas ventilasi yang baik, pencahayaan yang buruk di dalam ruangan, kepadatan hunian dalam rumah dan bahan bangunan didalam rumah. Selain lingkungan rumah yang mempengaruhi kejadian tuberkulosis keadaan lingkungan fisik, lingkungan biologis dan lingkungan sosial yang kurang baik juga akan dapat merugikan kesehatan dan dapat mempengaruhi penyakit tuberkulosis dan pada akhirnya mempengaruhi tingginya kejadian tuberkulosis (Muaz, 2014).

Kualitas lingkungan fisik rumah yang tidak memenuhi syarat kesehatan merupakan faktor risiko penyakit tuberkulosis paru lingkungan fisik rumah yang tidak sehat memegang peranan penting dalam penularan dan perkembangbiakan Mycobacterium tuberculosis. Menurut Notoatmojo, 2010.
Faktor resiko kejadian TB adalah likungan fisik, dan diperjelas lagi oleh Ahmadi (2010) yang menyatakan bahwa rumah tidak sehat merupakan salah satu reservoir atau tempat yang baik dalam menularkan penyakit tuberkolosis. Dengan kondisi fisik yang kurang memenuhi syarat, maka rumah bisa menjadi media penularan penyakit, khususnya TB Paru.

Ventilasi tetap berperan sebagai salah satu faktor risiko dilihat dari fungsinya sebagai tempat pertukaran aliran udara secara terus menerus untuk membebaskan udara ruangan dari bakteri-bakteri, terutama bakteri patogen seperti tuberkulosis. Upaya yang dapat dilakukan dengan membuka pintu dan jendela setiap pagi hari, mengupayakan sinar matahari masuk ke dalam rumah dengan memasang genteng kaca plastik agar tidak gelap dan mengurangi kelembaban serta dapat membunuh kuman dan bibit penyakit. Kondisi sanitasi lingkungan yang buruk dapat menjadi media penularan penyakit. Terjadinya penyakit berbasis lingkungan disebabkan karena adanya interaksi antara manusia dengan lingkungan. Terutama lingkungan rumah yang mana masyarakat menghabiskan banyak waktunya di rumah. Apabila sanitasi lingkungan rumah tidak diperhatikan, maka berpotensi menimbulkan suatu penyakit. Menurut Achmadi (2011) beberapa penyakit berbasis lingkungan diantaranya, Tuberkulosis (TB) 
Sesuai hasil observasi pada waktu melakukan penelitian, ditemukan rumah responden pada waktu pagi hari pintu maupun jendela rumah jarang dibuka, sehingga tidak ada cahaya matahari yang masuk maupun pergantian udara dengan baik, hal ini karena perilaku dan pengetahuan keluarga penderita TB Paru yang kurang, sehingga menjadikan rumah tidak layak huni. Selain perilaku yang kurang baik kondisi fisik rumah penderita TB paru tidak layak karena memang keterbatasan dana untuk membuat rumah layak, karena tidak mempu membuat dinding, cerobong asap yang baik.

\section{Kesimpulan}

Struktur rumah dan lingkungannya yang tidak memenuhi syarat kesehatan merupakan faktor resiko sebagai sumber penularan berbagai penyakit, salah satunya yaitu penyakit tuberkulosis. Selain itu, penderita TB akan mudah menularkan penyakit TB di tempat yang kondisi lingkungannya kurang baik, seperti ruangan yang berventilasi buruk, ruangan yang sempit dan lembab misalnya rumah yang tidak memenuhi syarat kesehatan, tempat kerja tambang, penjara, dan lain-lain

\section{DAFTAR PUSTAKA}

Castillo-Chavez, C. dan Song, B. , , 2004, Dinamical Models of Tuberculosis and Their Aplication. Math. Biosci. and Eng
Hiswani, 2009, Tuberkulosis merupakan Penyakit Infeksi Yang Masih Menjadi. Masalah. Kesehatan. Masyarakat. Available from: http://library. usu. ac. $\mathrm{id} /$ download/fkm-hiswani6. pdf 2009). Download on 12. Desember 2017

Litbang Kesehatan, 2000, Pedoman Nasional Penanggulangan Tuberkulosis. Jakarta: Dinas. P2M.

Mason, Robert J. et al. 2005. Murray and Nadel's Textbook of Respiratory Medicine. Edisi 4 Vol. 1. Philadelphia: Elsevier Saunders

Muaz, F. 2014. Faktor-Faktor Yang Mempengaruhi Kejadian Tuberkulosis Paru Basil Tahan Asam Positif Di Puskesmas Wilayah Kecamatan Serang Kota Serang Tahun 2014. Skripsi Fakultas Ilmu Kesehatan dan Kedokteran Universitas Islam Negeri Syarif Hidayatulloh Jakarta

Notoadmojo, Sukidjo, 2003, Pendidikan Dan Perilaku Kesehatan, Jakarta : PT Rineka. Cipta

Notoatmodjo, 2007, Pendidikan dan Perilaku kesehatan. Cetakan 2 Jakarta:PT. Rineka Cipta.

Suyono. 2005. Pokok Bahan Modul Perumahan dan Pemukiman Sehat. Jakarta: Pusdiknaker.

Umar Fahmi. (2005) Manajemen Penyakit Berbasis Wilayah. Penerbit. Buku Kompas. Jakarta. Aditama,

Walton, P. 1991. Environment Health. New York : Widya Medika

World Health Organization. World Global Tuberculosis Control 2010. Geneva World Health Organization.

Sastroasmoro, S., \& Ismael, S. (2011). Dasardasar metodologi penelitian klinis. Jakarta: Sagung

Seto, 372. 
